\title{
Phacoemulsification under Topical Anesthesia in a Tertiary Care Hospital
}

\author{
Sheikh Sajjad ${ }^{1}$, Hina Kounsar ${ }^{2}$, Suhail Raheem Rather ${ }^{3}$ \\ ${ }^{1}$ Professor/ HOD, Department of Ophthalmology, SKIMS-MCH, Bemina, Srinagar, Jammu and Kashmir \\ ${ }^{2}$ Senior Resident, Department of Ophthalmology, SKIMS-MCH, Bemina, Srinagar, Jammu and Kashmir \\ ${ }^{3}$ Medical Officer, Department of Health and Family Welfare
}

Corresponding Author: Hina Kounsar

\begin{abstract}
Introduction: The use of topical anaesthesia for cataract surgery dates back to 1884 when Knapp used 5\% cocaine to anaesthetize cornea. The advancement in cataract surgery techniques like small stepped, self-sealing corneal incisions, phacoemulsification and advanced intraocular lenses has allowed the use of topical anaesthesia thus reducing surgical time and need of akinesia.
\end{abstract}

Materials and Methods: Prospective noncomparative evaluation of patients' and surgeon's satisfaction under topical anaesthesia. All patients received topical anesthesia with proparacaine $0.5 \%$. A 10 -point visual analogue scale was given to patients to rate the level of pain felt during the operation. Also, the level of patient satisfaction, the need for supplemental anaesthesia, level of ocular motility, surgical complications and postoperative visual acuity were recorded.

Results: Total number of cases were 156 out of which 86 (55.1\%) were males and 70 (44.9\%) were females. Nuclear sclerosis was most common type of cataract followed by mixed opacities. Majority of patients had no intraoperative movement and $30.8 \%$ of patients had some movement. Surgeon was dissatisfied in only $12.2 \%$ cases who had disturbing movements during surgery. Although majority of patients felt no pain (68\%) or mild pain (23.7\%) during surgery $8.3 \%$ cases had moderate to severe pain which required supplemental intracameral lidocaine.

Conclusion: Topical anaesthesia is cost effective, provides high patient comfort during surgery, is less stressful for the patient, saves considerable time and complications compared to regional anaesthesia.

Key Words: topical anaesthesia, phacoemulsification, pain assessment, surgeon`s satisfaction

\section{INTRODUCTION}

The use of topical anaesthesia for cataract surgery dates back to 1884 when Knapp used 5\% cocaine to anaesthetize cornea (1). It failed to gain acceptance among surgeons at that time because of need of akinesia during surgery. The advancement in cataract surgery techniques like small stepped, self-sealing corneal incisions, phacoemulsification and advanced intraocular lenses has allowed the use of topical anaesthesia thus reducing surgical time and need of akinesia (2-6). Phacoemulsification is now increasingly being performed under topical anaesthesia with studies demonstrating results comparable with regional blocks (7-12). It has become preferred mode of anaesthesia for phacoemulsification cataract surgery at our center as it saves considerable amount of time and complications associated with other blocks.

\section{MATERIALS AND METHODS}

Prospective non-comparative evaluation of patients' and surgeon's satisfaction under topical anaesthesia. All surgical procedures were performed in the SKIMS-MCH by the same surgeon. Patients 
were counselled regarding the procedure and were advised to cooperate with the surgeon and avoid movement of eyes and to fix eye towards operating microscopic light source. One fifty six patients were included in the study. All patients received topical anesthesia with proparacaine $0.5 \%$. The eye drops were instilled into the eye to be operated fifteen minutes prior to surgery. Instillation was done three times, at an interval of five minutes.

Most patients were administered dilating drops, phenylephrine $2.5 \%$ and cyclopentolate $1 \%$, one drop, three times each, 15 minutes apart, starting 1 hour before surgery.

No bridle rectus suture was used. Clear corneal incision was given which was very small (about $3.5 \mathrm{~mm}$ ). Continuous curvilinear capsulorrhexis (CCC) of 4-5 mm was done. After doing the hydroprocedure, the lens nucleus was phacoemulsified by stop and chop technique and direct chop technique. Cortical matter was aspirated out using two separate canulas (bimanual I/A). Viscoelastic material was injected. The foldable IOLs were used. The viscoelastic was then aspirated. $0.5 \mathrm{cc}$ vigamox was injected intracamerally. The side port hydration was done. The surgeon's satisfaction was determined by patient's cooperation regarding movement of eye during procedure.

Pain assessment: A 10-point visual analogue scale was given to patients to rate the level of pain felt during the operation. Patients were asked to inform the surgeon if they experienced any pain at any point of the surgery. If so, additional anesthesia was given. Also, the level of patient satisfaction, the need for supplemental anaesthesia, level of ocular motility, surgical complications and postoperative visual acuity were recorded.

\section{INCLUSION CRITERIA:}

- Cases of both sexes.

- Significant cataract causing impairment of visual functions not correctable by glasses.

- Patients who gave informed written consent.

\section{EXCLUSION CRITERIA:}

- Patients with types of cataracts other than senile cataract

- uncooperative patients

- Lidocaine, proparacaine sensitivity.

- Patients with hearing disorders, dementia, Asthma.

\section{RESULT}

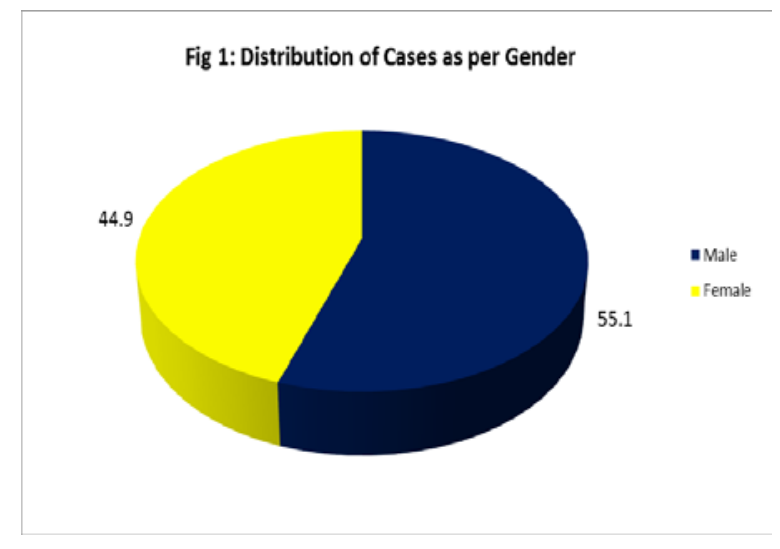

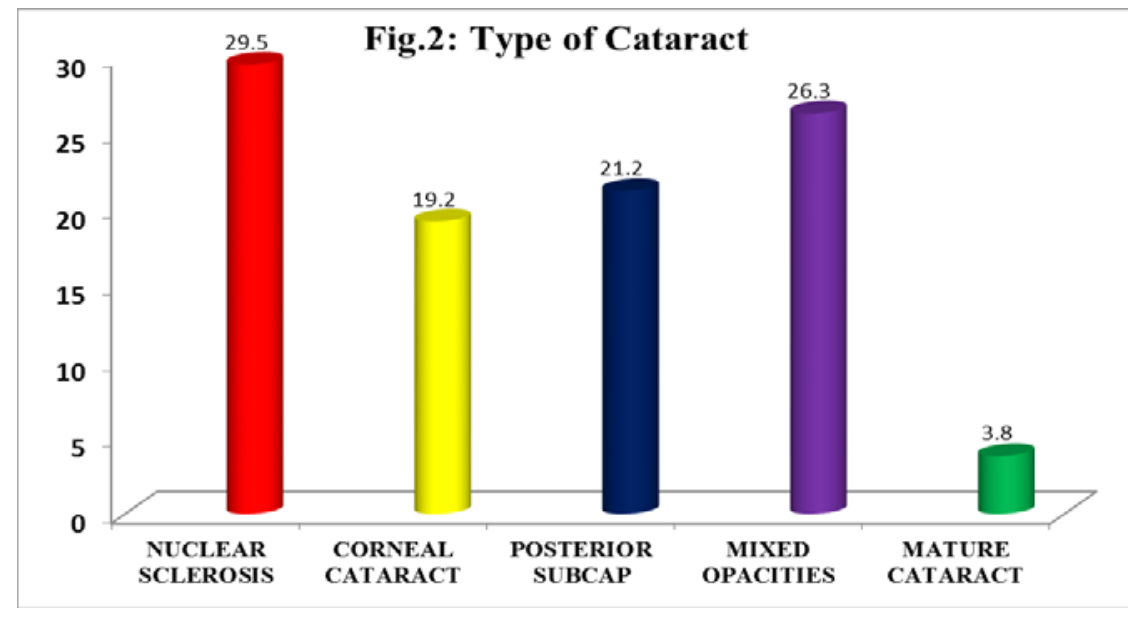


Total number of cases were 156 out of which 86 (55.1\%) were males and 70 (44.9\%) were females Fig 1.

Nuclear sclerosis was most common type of cataract followed by mixed opacities Fig 2.

Almost $90 \%$ of the cases had visual acuity $6 / 60$ or less. $46.8 \%$ of cases had visual acuity 6/60, 37.2\% cases had finger counting vision, $10.3 \%$ had $6 / 36$ and $5.8 \%$ could perceive hand movements only Table 1.

\begin{tabular}{|l|l|l|}
\hline \multicolumn{3}{|c|}{ Table 1: Pre-operative Best corrected Visual Acuity } \\
\hline Vision & No. of Cases (n) & \% of Cases \\
\hline HM & 9 & 5.8 \\
\hline FC & 58 & 37.2 \\
\hline $6 / 60$ & 73 & 46.8 \\
\hline $6 / 36$ & 16 & 10.2 \\
\hline Total & 156 & 100.0 \\
\hline
\end{tabular}

Majority of patients had no intraoperative movement and $30.8 \%$ of patients had some movement. Surgeon was dissatisfied in only $12.2 \%$ cases who had disturbing movements during surgery Table 2.

\begin{tabular}{|l|l|l|}
\hline \multicolumn{3}{|c|}{ Table 2: Intra-operative Ocular Movement } \\
\hline Movement & No. of cases (n) & \%age of Cases \\
\hline No Movement & 89 & 57 \\
\hline Some Movement & 48 & 30.8 \\
\hline Disturbing Movement & 19 & 12.2 \\
\hline Total & 156 & 100.0 \\
\hline
\end{tabular}

Although majority of patients felt no pain $(68 \%)$ or mild pain $(23.7 \%)$ during surgery $8.3 \%$ cases had moderate to severe pain which required supplemental intracameral lidocaine Table 3.

\begin{tabular}{|l|l|l|}
\hline \multicolumn{3}{|c|}{ Table 3: Intraoperative Pain } \\
\hline Degree of pain & No. of cases (n) & \%age of cases \\
\hline No pain & 106 & 68 \\
\hline Mild pain & 37 & 23.7 \\
\hline Moderate to severe & 13 & 8.3 \\
\hline Total & 156 & 100.0 \\
\hline
\end{tabular}

Postoperative visual acuity was 6/6 in majority of cases Table 4.

\begin{tabular}{|l|l|l|}
\hline \multicolumn{3}{|c|}{ Table 4 : Post-Operative BCVA } \\
\hline Vision & No. of Patients (n) & \% of Patients \\
\hline $6 / 6$ & 107 & 68.6 \\
\hline $6 / 9$ & 36 & 23.0 \\
\hline $6 / 12$ & 9 & 5.8 \\
\hline $6 / 18$ & 4 & 2.6 \\
\hline Total & 156 & 100.0 \\
\hline
\end{tabular}

Posterior capsular rent was noted in 6 cases among which 2 had vitreous loss.

\begin{tabular}{|l|l|l|}
\hline \multicolumn{3}{|c|}{ Table 5: PATIENT SATISFACTION } \\
\hline EXTREMELY SATISFIED & 101 & 64.7 \\
\hline SATISFIED & 46 & 29.5 \\
\hline DISSATISFIED & 9 & 5.8 \\
\hline
\end{tabular}

Only 9 (5.8\%) patients were dissatisfied with surgery under topical anaesthesia Table 5.

\section{DISCUSSION}

Cataract surgery is the most commonly performed surgery in ophthalmology. Carl Koller in 1884 demonstrated the use of topical cocaine to anaesthetize cornea (13). Knapp used a 5\% cocaine formulation to perform cataract surgery under topical anaesthesia in same year. Due to popularization of retrobulbar \& peribulbar anaesthesia this technique failed to gain acceptance. Fichman in 1992 reintroduced the use of topical anaesthesia for phacoemulsification $(13,14)$.

$$
\text { Topical anaesthesia for }
$$

phacoemulsification cataract surgery has several advantages compared to peribulbar or retrobulbar anaesthesia, as it eliminates the risk of globe perforation, retrobulbar haemorrhage and damage to orbital contents. No post-operative ptosis or diplopia is seen. Preservation of full ocular movements gives an edge to surgeon by improving surgical access if needed. The technique is also economical, avoids undesirable cosmetic adverse effects, and allows instant visual rehabilitation (15-25).

Numerous studies have reported topical anaesthesia to be safe and efficacious mode of anaesthesia. Some of the commonly employed agents for providing topical anaesthesia during phacoemulsification include lidocaine (4\%), proparacaine $(0.5 \%)$ and ropivacaine $(1 \%)$.

Topical anaesthesia is more rapid and acceptable to patients. A surgeon has to win patients confidence by making the patient comfortable during the procedure with constant surgeon-patient communication and telling the patient to keep the eye still for a moment particularly 
during capsulorhexis, IOL insertion and it also requires full cooperation of the patient $(26,27)$. In our study patient as well as surgeon were comfortable in maximum number of cases.

Most studies have reported that the patient perceived pain to be low and tolerable under topical anaesthesia compared to those receiving peribulbar anaesthesia (28). Topical anaesthesia supplemented with intracameral lidocaine has been proved to be safe and efficacious (29). In our study we also found that patient experienced No or mild pain under topical anaesthesia. Moderate to severe pain was felt in few cases which were supplemented with intracameral lidocaine $0.1-0.5 \mathrm{~mL}$ which was injected into the anterior chamber (30).

In our study 6 patients had posterior capsular rupture out of which 2 patients had vitreous loss. However, intracameral lidocaine proved adequate for additional anterior vitrectomy. Though the intraoperative complications were not associated with the type of anaesthesia.

\section{CONCLUSION}

Topical anaesthesia has found large acceptance because it's cost effective, provides high patient comfort during surgery, is less stressful for the patient, saves considerable time and complications compared to regional anaesthesia. Surgery related pain and patient discomfort were significantly lesser in patients along with topical anesthesia. Earliest visual rehabilitation as the patient starts seeing within an hour of surgery with dark glasses on for photophobia is an advantage. There is no need of overnight bandaging and the eye drops can be started immediately. Topical anaesthesia is safe \& satisfactory alternative for clear corneal phacoemulsification in selected cataract patients in hands of experienced cataract surgeon.

\section{Acknowledgement: None}

Conflict of Interest: None

\section{Source of Funding: None}

\section{Ethical Approval: Approved}

\section{REFERENCES}

1. Altman AJ, Albert DM, Fournier GA. Cocaine's use in ophthalmology: our 100year heritage. Surv Ophthalmol. 1985 Feb; 29(4):300-6.

2. Boyd BF (1975-1976) Personal interview between the editor and RC Troutman, D Paton, S Ryan. Present trends in incision closure of the cataract wound. Highlights Ophthalmol 14: 176-204.

3. Fichman RA (1993) The clear-corneal incision and astigmatism strategies. In: Fine IH, Fichman RA, Grabow HB, (eds), ClearCorneal Cataract Surgery and Topical Anesthesia. Slack, Thorofare, NJ: 72-76.

4. Linebarger EJ, Hardten DR, Shah GK, Lindstrom RL (1999) Phacoemulsification and modern cataract surgery. Surv Ophthalmol 44: 123-147.

5. Malik A, Fletcher EC, Chong V, Dasan J (2010) Local anesthesia for cataract surgery. J Cataract Refract Surg 36: 133-152.

6. Yepez J, Cedeno de Yepez J \& Arevalo JF (1999) Topical anesthesia for phacoemulsification, intraocular lens implantation and posterior vitrectomy. J Cataract Refract Surg 25: 1161-1164.

7. Nielsen $\mathrm{P}(1995)$ A prospective evaluation of anxiety and pain with topical analgesia or retrobulbar anaesthesia for small incision cataract surgery. Eur J Implant Refract Surg 7:6-1

8. Duguid IG, Claoue CM, Thamby-Rajah Y, et al (1995) Topical anaesthesia for phacoemulsification surgery. Eye 9:456459

9. Zehetmayer M, Radax U, Skorpik C, et al.(1996) Topical versus peribulbar anesthesia in clear corneal cataract surgery. J Cataract Refract Surg 22:480-484

10. Patel BC, Burns TA, Crandall A, et al. (1996). A comparison of topical and retrobulbar anesthesia for cataract surgery. Ophthalmology 103:1196-12

11. Maclean H, Burton T, Murray A(1997) Pati ent comfort during cataract surgery with modified topical and peribulbar anesthesia. $\mathrm{J}$ Cataract Refract Surg 23:277-283.

12. Nielsen PJ, Allerod CW(1998) Evaluation of local anesthesia techniques for small 
incision cataract surgery. J Cataract Refract Surg 24:1136-1144.

13. Fichman RA (1992) Topical eye drops replace injection for anesthesia. Ocular Surgery News 1: 20-21.

14. Fichman RA (2001) Topical technique appear safer in patient with anticoagulant Anesthesia. Intensive Care 29: 8-11.

15. Nicoll JM, Acharya PA, Ahlen K, et al. (1987). Central nervous system complications after 6000 retrobulbar blocks. Anesth Analg 66:1298-302

16. Edge KR, Nicoll JM(1993) Retrobulbar hemorrhage after 12,500 retrobulbar blocks. Anesth Analg 76:1019-1022.

17. Davis DB, Mandel MR(1994) Efficacy and complication rate of 16,224 consecutive peribulbar blocks. A prospective multicenter study. J Cataract Refract Surg 20:327-337.

18. C. M. Morgan, H. Schatz, A. K. Vine et al., "Ocular complications associated with retrobulbar injections," Ophthalmology, vol. 95, no. 5, pp. 660-665, 1988.

19. Sullivan KL, Brown GC, Forman AR, et al. "Retrobulbar anesthesia and retinal vascular obstruction," Ophthalmology, vol. 90, no. 4, pp. 373-377, 1983

20. Duker JS, Belmont JB, Benson WE, et al. (1991) Inadvertent globe perforation during retrobulbar and peribulbar anesthesia. Patient characteristics, surgical management, and visual outcome. Ophthalmology 98:519-526.

21. Hay A, Flynn HW, Hoffman JI, et al. (1991). Needle penetration of the globe during retrobulbar and peribulbar injections. Ophthalmology 98:1017-1024.

22. Rainin EA, Carlson BM (1985). Postoperative diplopia and ptosis. A clinical hypothesis based on the myotoxicity of local anesthetics. Arch Ophthalmol. 103:13371339.
23. Esswein MB, von Noorden GK (1993). Paresis of a vertical rectus muscle after cataract extraction. Am J Ophthalmol 116:424- 430.

24. Claoue C, Lanigan C (1997) Topical anesthesia for cataract surgery. Aust N Z J Ophthalmol 25: 265-268.

25. Nielsen PJ. Immediate visual capability after cataract surgery: topical versus retrobulbar anesthesia. J Cataract Refract Surg1995213024

26. Rewri P, Choudhary A, Pandey SM et al. Topical Anaesthesia For Cataract Surgery: Patient`s perspective. DJO 2021;31:32-36

27. Mathew MRK, Webb LA, Hill R. Surgeon experience and patient comfort during clear corneal phacoemulsification under topical local anesthesia. J Cataract Refract Surg. 2002 Nov;28(11):1977-81

28. O'Brien PD, Fulcher T, Wallace D, et al. Patient pain during different stages of phacoemulsification using topical anesthesia. J Cataract Refract Surg. 2001 Jun; 27(6):880-3.

29. Chuang LH, Yeung L, Ku WC, et al. Safety and efficacy of topical anesthesia combined with a lower concentration of intracameral lidocaine in phacoemulsification: paired human eye study. $J$ Cataract Refract Surg. 2007;33(2):293-296.

30. Tseng SH, Chen FK. A randomized clinical trial of combined topical-intracameral anesthesia in cataract surgery. Ophthalmology 1999; 106: 1644-5

How to cite this article: Sajjad S, Kounsar H, Rather SR. Phacoemulsification under topical anesthesia in a tertiary care hospital. International Journal of Research and Review. 2021; 8(11): 378-382. DOI: https://doi.org/10. 52403/ijrr.20211148 